\title{
Letramentos Digitais e Desenvolvimento do profissional da Área de Vestuário
}

\section{Juliana Rangel de Morais Pimentel ${ }^{1}$, Raimundo Claudio da Silva Vasconcelos ${ }^{2}$, Veruska Ribeiro Machado ${ }^{3}$}

\author{
${ }^{1}$ Instituto Federal de Brasília, Campus Taguatinga \\ QNM 40, AE 01 - CEP 72146-000 - Taguatinga - DF - Brasil \\ juliana.pimentel@ifb.edu.br, raimundo.vasconcelos@ifb.edu.br, \\ veruska.machado@ifb.edu.br
}

\begin{abstract}
Increasing educational use of software in general education as well as an educational approach of digital technologies has been successful in the classroom. In this sense, this article aims to report on the experience of the adoption of AMCAP software that allows the development of cognitive competence related to the recognition of the textile structures in the teachinglearning process of the students in the curricular component Textiles and Products, in Technical Course in Clothing located in the satellite city of Taguatinga, in Brasilia. As results, it was verified that the use of TDICs had a positive impact, contributing to increase students' problem-solving.
\end{abstract}

Resumo. O crescente uso educativo de softwares no ensino em geral bem como o enfoque educacional de tecnologias digitais tem se mostrado positivo na sala de aula. Neste sentido, este artigo tem por objetivo relatar a experiência da adoção do software AMCAP que permite o desenvolvimento da competência cognitiva relacionada ao reconhecimento das estruturas têxteis no processo de ensino-aprendizagem dos estudantes no componente curricular Materiais Têxteis e Produtos, do Curso Técnico em Vestuário localizado na cidade satélite de Taguatinga, em Brasília. Como resultados, verificou-se que o uso das TDICs impactou positivamente para resolução de problemas por parte dos estudantes.

\section{Introdução}

A sociedade experimenta avanços diuturnos do mundo digital, o que traz, ao mesmo tempo, possibilidades, mas também desafios cada vez mais complexos. Nesse sentido, competências diversificadas são requeridas das pessoas para que se insiram em um mundo que tem as tecnologias digitais como parte integrante.

Em consonância com esse contexto, a Organização para Cooperação e Desenvolvimento Econômico (OCDE) desenvolve um programa denominado Avaliação Internacional das Competências dos Adultos (PIAAC) voltado para avaliação e análise de habilidades para atuação em contextos diversos. Esse programa considera habilidades cognitivas e de trabalho necessárias para que os indivíduos participem da sociedade. Como competências cognitivas, o PIACC considera leitura, escrita, aritmética e uso das Tecnologias Digitais de Informação e Comunicação (TDICs). E, na avaliação direta que realiza, leva em conta a 
VIII Congresso Brasileiro de Informática na Educação (CBIE 2019)

Anais do XXV Workshop de Informática na Escola (WIE 2019)

resolução de problemas em contexto de intensa tecnologia: capacidade de usar tecnologia para resolver problemas e realizar tarefas complexas.

Essas competências avaliadas pelo PIACC ajudam-nos a refletir sobre o nosso papel na educação escolar nesse contexto atual, no qual, para Moran (2013), o mundo físico dialoga com o digital, "com suas atividades de pesquisa, lazer, de relacionamento e outros serviços e possibilidades e integração, que impactam profundamente a educação escolar e as formas de ensinar e aprender (...)” (p. 14).

Sendo assim, torna-se imperativo agregar aos currículos os letramentos digitais. Neste trabalho, o conceito de letramento digital será tomado em uma perspectiva ampliada, conforme apontado por Buzato

Letramentos digitais (LDs) são conjuntos de letramentos (práticas sociais) que se apóiam, entrelaçam e apropriam mútua e continuamente por meio de dispositivos digitais para finalidades específicas, tanto em contextos socioculturais geograficamente e temporalmente limitados, quanto naqueles construídos pela interação mediada eletronicamente. (BUZATO, 2006, p. 16)

Com base nessas questões, parte-se do princípio, neste texto, de que a educação formal deve, em todas as suas modalidades, incorporar os letramentos digitais em uma perspectiva crítica nos currículos. Para isso, é preciso buscar soluções interativas, que sejam exploradas por meio de metodologias ativas e participativas.

De acordo com essa perspectiva, este texto tem como objetivo apresentar o relato de uma experiência que ocorreu no âmbito da educação profissional, em um curso técnico em vestuário, no que se refere ao uso de tecnologias e ao desenvolvimento dos letramentos digitais dos estudantes. Cabe destacar que este relato faz parte de um projeto-piloto desenvolvido por professores de áreas interdisciplinares, por meio do Grupo de Pesquisa Formação de Professores em Tecnologia Educacional (Proted).

\section{Letramentos digitais e a formação do profissional da área de vestuário}

Esta seção contextualiza o curso técnico em vestuário, destacando-se o papel dos letramentos digitais na formação desses profissionais.

O curso técnico em vestuário pertence ao eixo tecnológico de produção industrial. A organização curricular dos cursos pertencentes a esse eixo prevê: ciência, tecnologia e inovação; investigação tecnológica; empreendedorismo, cooperativismo e associativismo; tecnologias de comunicação e informação etc (MEC/SETEC, 2016). A partir dessa proposta de organização curricular, pode-se depreender a necessidade de incorporar ao currículo dos cursos desse eixo os letramentos digitais.

Nas últimas décadas, as empresas da área de vestuário iniciaram suas adequações aos novos padrões estabelecidos pela chegada da tecnologia, no intuito de se manterem competitivas no mercado, realizando aquisições de maquinários automatizados, com instalações de softwares computacionais que ajudam a otimizar os processos produtivos. 
VIII Congresso Brasileiro de Informática na Educação (CBIE 2019)

Anais do XXV Workshop de Informática na Escola (WIE 2019)

Essas mudanças geram cada dia mais exigências no domínio das tecnologias digitais para os novos perfis profissionais, para que consigam desempenhar suas tarefas de maneira rápida e eficiente no seu local de trabalho. Essa habilidade passou a ser obrigatória, desde que o fenômeno da $4^{a}$ Revolução Industrial, também conhecida como Indústria 4.0, foi inserido no contexto de vários segmentos profissionais.

Essas mudanças na área de vestuário, em decorrência, principalmente, das tecnologias digitais, exigem que a formação dos profissionais que atuarão na área seja capaz de prepará-los para esse contexto. Ante essa realidade, os componentes curriculares do técnico em vestuário precisam dialogar com as tecnologias digitais utilizadas no mundo do trabalho. A seguir, apresenta-se uma proposta para esse diálogo desenvolvida no componente curricular Materiais Têxteis e Produtos.

\section{Letramentos digitais e a formação do profissional da área de vestuário: um relato de experiência}

Com o objetivo de agregar os letramentos digitais ao currículo do técnico em vestuário, começaram a ser desenvolvidos alguns projetos-piloto visando ao desenvolvimento de metodologias mais ativas, participativas e adaptadas aos estudantes. Neste texto, consta o relato da experiência desenvolvida no componente curricular Materiais Têxteis e Produtos, do Curso Técnico em Vestuário.

Nesta disciplina, os alunos precisam ter conhecimento sobre os diferentes tipos de tecidos, dentre eles, os tecidos planos, muito utilizados na confecção de camisas, calças, saias e blazers. Para que seja feita essa diferenciação entre os diversos tipos de tecidos, os alunos necessitam compreender, por exemplo, a forma de entrelaçamento dos fios de trama e urdume que compõem esses tecidos planos. $\mathrm{Na}$ figura 1, é possível ilustrar esse tipo de entrelaçamento.

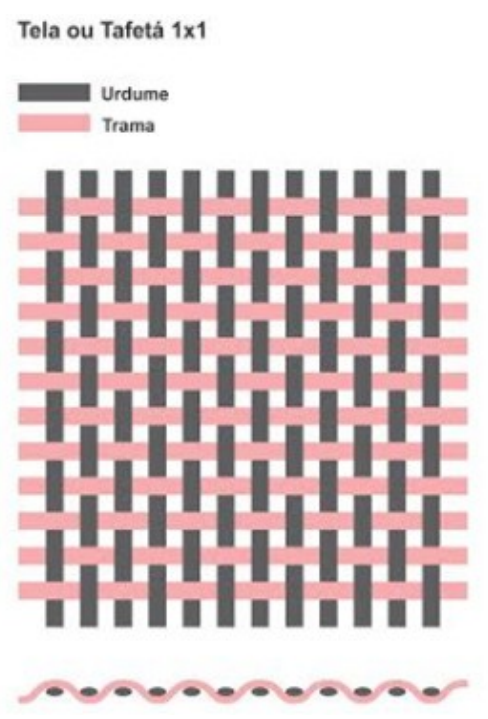

Figura 1: Representação do entrelaçamento dos fios de trama e urdume em tecidos planos. Fonte: Autores, 2015

Considerando as especificidades dessa disciplina, passou-se a adotar como recurso para o desenvolvimento das aulas uma ferramenta digital com o objetivo de facilitar 
VIII Congresso Brasileiro de Informática na Educação (CBIE 2019)

Anais do XXV Workshop de Informática na Escola (WIE 2019)

a compreensão do conteúdo. Adotou-se, para isso, o uso do software AMCAP (sistema operacional: Windows XP), que auxilia na captura de imagens do material analisado (tecido plano), produzidas pelo microscópio digital USB portátil, Marca KKMOON, Modelo 1000X ZOOM/8X LEDS, com sensor CMOS de imagem, que se conecta a um computador e este, por sua vez, conecta-se a um equipamento que projeta as imagens do material têxtil no quadro. Na figura 2, é possível ilustrar a imagem projetada no quadro, capturada pelo microscópio digital, por meio do sistema AMCAP e a imagem do modelo do microscópio.

Figura 2:

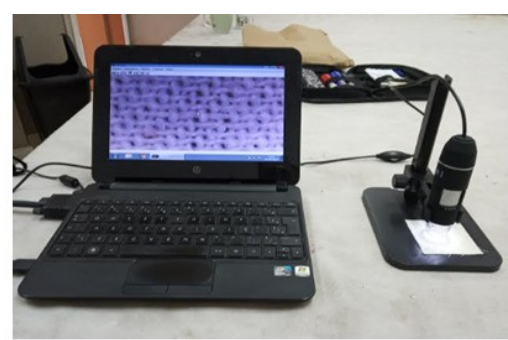

a) Microscópio eletrônico conectado ao computador.

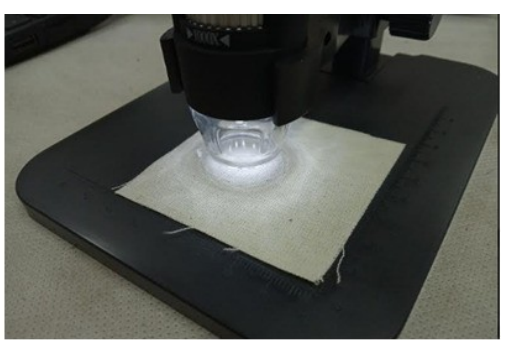

b) Amostra de tecido posicionada sob a lente do microscópio eletrônico para análise.

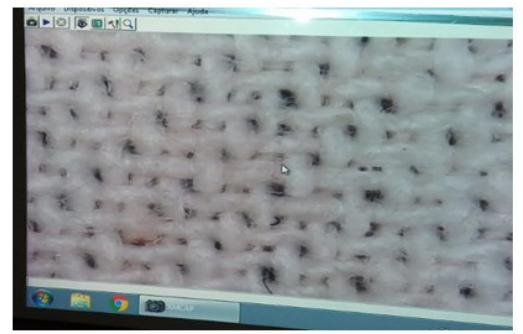

c) Projeção do material em análise (tecido) no quadro.

Representação da imagem capturada pelo microscópio eletrônico, por meio do sistema AMCAP e do modelo do microscópio eletrônico. Fonte: Autores, 2019.

Como resultados da inserção dessas ferramentas para o ensino do conteúdo ministrado na disciplina Materiais Têxteis e Produtos, é possível verificar uma maior participação dos alunos nas aulas, interesse maior pelo conteúdo ministrado e uma melhor compreensão das informações, visto que o uso do software, juntamente com os outros equipamentos digitais, permite atingir o objetivo principal: a aprendizagem dos alunos. Destaca-se que essa compreensão deve-se ao fato de os estudantes poderem visualizar a forma de entrelaçamento dos fios de trama e urdume que compõem esses tecidos. Sem o uso do software, as explicações eram apenas teóricas.

Constatou-se também que a adoção do software AMCAP permite o desenvolvimento da competência cognitiva relacionada às tecnologias digitais, bem como permite que se desenvolvam habilidades de resolução de problemas em contexto de intensa tecnologia: capacidade de usar tecnologia para resolver problemas e realizar tarefas complexas na área de vestuário, o que é extremamente relevante na educação profissional.

Por fim, observou-se que o domínio das tecnologias digitais acarreta impactos relevantes no que diz respeito ao ensino-aprendizagem, pois os métodos pedagógicos convencionais não são mais suficientes para suprir as expectativas dos 
estudantes em relação ao interesse e fixação dos conteúdos. Isso aponta para a necessária reestruturação dos currículos, de suas metodologias e recursos no intuito de tornar o conhecimento disseminado dentro da escola mais significativo.

\section{Considerações Finais}

Na introdução deste texto, fez-se um questionamento acerca do nosso papel na educação escolar nesse contexto atual. Nossas ideias coadunam-se com as de Moran (2013), para quem nosso papel é de "ser mediadores interessantes, competentes e confiáveis entre o que a instituição propõe em cada etapa e o que os alunos esperam, desejam e realizam” (p. 12).

Sendo assim, os professores de áreas interdisciplinares, por meio do Grupo de Pesquisa Formação de Professores em Tecnologia Educacional (Proted), reconhecem ser imprescindível agregar os letramentos digitais aos currículos e, por isso, buscam soluções interativas por meio de recursos com os quais os alunos se identificam, com o desenvolvimento de aplicativos, uso de softwares computacionais e recursos audiovisuais, no intuito de promover aulas que explorem metodologias ativas e participativas e que, assim, tornem os conteúdos mais significativos, contextualizados e, consequentemente, atrativos. O relato de experiência aqui apresentado ilustra parte de um projeto-piloto que visa a propor o diálogo dos componentes curriculares do curso técnico em vestuário com as tecnologias digitais.

\section{Referências}

- BUZATO, M. E. K. Letramentos digitais e formação de professores. São Paulo: Portal Educarede. 2006. Disponível em: http://www.educarede.org.br/educa/img_conteudo/marcelobuzato.pdf. Acesso em: 12 jul. 2019.

- MÉLIO, D. E de.; OLIVEIRA, A. X de. Os Artefatos Digitais na Educação Superior: possibilidades didáticas para o ensino de conceitos científicos à luz da teoria histórico-cultural, cap. 1 do livro Metodologias Pedagógicas Inovadoras: contextos da educação básica e da educação superior. Curitiba: Editora IFPR, 2018. v.2. p. 12. ISBN: 978-85-54373-03-0.

- MORAN, J. M. Ensino e aprendizagem inovadores com apoio de tecnologias. In: MORAN, J. M.; MASETTO, M. T.; BEHRENS, M. A. Novas tecnologias e mediação pedagógica. Campinas, SP: Papirus, 2013. p. 11-72.

- OECD. Programme for the International Assessment of Adult Competencies (PIAAC). Disponível em: https://www.oecd.org/skills/piaac/. Acesso em: 13 jul. 2019.

- SETEC. Catálogo Nacional de Cursos Técnicos. Brasília: MEC, 2016. Disponível em: http://portal.mec.gov.br/docman/novembro-2017-pdf/77451cnct-3a-edicao-pdf-1/file. Acesso em: 12 jul. 2019. 